\title{
Continuous intracorneal ring implantation for treatment of myopic astigmatism
}

This article was published in the following Dove Press journal: International Medical Case Reports Journal

\author{
Suzan Amana Rattan \\ Department of Surgery, Al-Kindy \\ College of Medicine, University of \\ Baghdad, Baghdad, Iraq
}

Correspondence: Suzan Amana Rattan Al-Kindy College of Medicine, University of Baghdad, Al-Nahdhah Square, Baghdad, Iraq

Tel +964 7702750754

Email suzanophthalmologist@gmail.com

\begin{abstract}
We report a case of myopic astigmatism, not eligible for laser vision correction and with an anterior chamber depth below that recommended for application of phakic implantable collamer lens. In this case, the only refractive surgery option that remained for the patient was intracorneal ring implantation. The aim of the current presentation was to document the clinical and refractive outcomes after continuous intracorneal ring implantation in both eyes in this patient with myopic astigmatism. The results presented were collected during a 4-year follow-up period. Surgery was performed at Lasik specialty center, Baghdad, Iraq, in 2013.
\end{abstract}

Keywords: MyoRing, myopic astigmatism, keratoconus

\section{Introduction}

In general, there are three approaches for correction of myopic refractive error: 1) laser kerato refractive procedures; 2) PICL implantation; and 3) refractive lens exchange.

Laser kerato refractive procedures have been used to treat a wide range of refractive errors and proved safety and effectivity for most of the treated cases.

Corneal thickness remains one of the most important physical limits to correction of myopic refractive error by laser, and the optical quality outcome may not be as good as desired when treating individuals with a higher refractive error.

In cases of moderate-to-high myopia, when laser kerato refractive procedure is inappropriate, or there is a risk for biomechanical instability of the cornea, ${ }^{1,2}$ and in the absence of contraindication, PICL is the best option. ${ }^{3-6}$

Refractive lens exchange is not a popular approach due to the increased risk of retinal detachment, particularly in eyes with long axial length $(>26 \mathrm{~mm})$ and loss of accommodation in young patients. ${ }^{7,8}$

Where laser kerato refractive approaches and PICL implantation are not possible, intracorneal ring is another option for treatment of individuals with myopia or myopic astigmatism refractive error.

The current case report details the clinical and refractive outcomes after intracorneal complete ring implantation (MyoRing) in both eyes in a patient with myopic astigmatism.

\section{Patient and method}

The patient was a 20-year-old male. His right eye UCVA was $<0.1$, BCVA was 0.6 , and manifest refraction was $-8.00 \mathrm{~s}-4.00 \mathrm{c} \times 100^{\circ}$. Minimum corneal thickness was found to be $501 \mu \mathrm{m}$ by ultrasonic pachymetry (Tomey SP-100). 
The Scheimpflug-Placido corneal topography (bon SIRIUS; CSO Italia) showed that the flattest simulated K value (SIM K1) was $43.96 \mathrm{D} \times 96^{\circ}$, the steepest simulated $\mathrm{K}$ value (SIM K2) was $45.54 \mathrm{D} \times 6^{\circ}$, average keratometry (K) was $44.74 \mathrm{D}$, and apex keratometry (K apex) was 45.88 D. ACD was $2.18 \mathrm{~mm}$, and iridocorneal angle was $35^{\circ}$. The photopic pupil diameter was $4.28 \mathrm{~mm}$, and the scotopic pupil diameter was $6.4 \mathrm{~mm}$.

For the left eye, UCVA was $<0.1$, BCVA was 0.6 , manifest refraction was $-8.00 \mathrm{~s}-3.5 \mathrm{c} \times 85^{\circ}$, SIM K1 was $44.43 \mathrm{D}$ $\times 83^{\circ}$, SIM K2 was $46.00 \mathrm{D} \times 173^{\circ}$, average $\mathrm{K}$ was $45.20 \mathrm{D}$, $\mathrm{K}$ apex was $45.9 \mathrm{D}$, and the thinnest ultrasonic pachymetry reading was $496 \mu \mathrm{m}$.

ACD was $2.41 \mathrm{~mm}$, and iridocorneal angle was $40^{\circ}$. The photopic and scotopic pupil diameters were 4.10 and $6.2 \mathrm{~mm}$, respectively. There were no clinical or topographic findings suggestive of KC, no corneal opacity, and no previous ocular surgery in either eye.

Written informed consent was provided by the patient for treatment using MyoRing, and for the preoperative and postoperative case details and topographic images to be included in a case report and published. The scientific and ethical committee of Al-Kindy College of Medicine, University of Baghdad, Baghdad, Iraq, approved this study.

\section{Procedure}

MyoRing (Dioptex, GmbH, Linz, Austria) is a complete deformable ring implant made from poly methyl methacrylate. Available diameters range from 5 to $7 \mathrm{~mm}$, while thicknesses range from 150 to $350 \mu \mathrm{m}$; the width of the ring is $0.5 \mathrm{~mm}$.

The surgical technique was the same for both eyes, and the two operations were performed by a single surgeon with a 2-week interval between the surgery in the right and left eyes. Surgery was performed under local anesthesia using topical tetracaine hydrochloride (Cooper) $0.5 \%$ eye drops, in three steps:

1. A femtosecond laser (Ziemer Ophthalmic Systems, Port, Switzerland) was used to create an $8 \mathrm{~mm}$ diameter pocket at a depth of $300 \mu \mathrm{m}$ with a closed circumference, except for a supero-temporal incision with a $4 \mathrm{~mm}$ width.

2. A $5 / 280$ diameter MyoRing was chosen for both eyes, according to the nomogram supplied by the manufacturer (Table 1). This nomogram is used to determine the dimension of the ring that should be used to achieve a specific refractive correction. The ring was compressed using special forceps to facilitate implantation through the incision.
Table I Nomogram for MyoRing selection, according to the spherical equivalent (SE)

\begin{tabular}{lll}
\hline $\begin{array}{l}\text { SE range } \\
\text { (diopters) }\end{array}$ & $\begin{array}{l}\text { MyoRing } \\
\text { thickness }(\boldsymbol{\mu m})\end{array}$ & $\begin{array}{l}\text { MyoRing } \\
\text { diameter }(\mathbf{m m})\end{array}$ \\
\hline-9.00 to -13.00 & 280 & 5 \\
-5.5 to -6.5 & 280 & 6 \\
-2.5 to -3.5 & 280 & 7 \\
\hline
\end{tabular}

3. The ring was positioned centrally inside the pocket. The temporal incision did not require suturing.

From the day of surgery, topical tobramycin-dexamethasone eye drops was prescribed for use four times daily for 1 week only.

Follow-up visits were on the first postoperative day, and at 1 week, 1 month, 6 months, 1 year, and 4 years postoperatively.

\section{Results}

At the week 1 postoperative follow-up visit, UCVA for the right eye was 0.5 , manifest refraction was $-0.50 \mathrm{~s}-1.25 \mathrm{c}$ $\times 168^{\circ}$, and BCVA was 0.6 . UCVA was stable at 0.6 at subsequent 1-month, 1-year, and 4-year postoperative follow-up visits.

At the 3-month postoperative follow-up visit, SIM K1 was $38.39 \times 174^{\circ}$, SIM K2 was $41.34 \times 84^{\circ}$, and average K was $39.81 \mathrm{D}$. These values were maintained during the 4 -year follow-up period.

There was a 4.2 D reduction in SIM K2, and the reduction in average $\mathrm{K}$ was $4.9 \mathrm{D}$, which was maintained throughout the follow-up period. Figure 1 shows the flattening effect of MyoRing on SIM K1 and SIM K2 on an anterior tangential map of the right eye generated by SIRIUS topography during the postoperative visits.

For the left eye, UCVA was 0.5, BCVA was 0.6 , and manifest refraction was $-1.5 \mathrm{c} \times 178^{\circ}$, at the week 1 postoperative follow-up. UCVA was 0.6 at 1 -month postoperative follow-up, and this value remained the same at the 1- and 4-year follow-up visits.

Regarding keratometry, a 4.5 D reduction in SIM K2 and $4.8 \mathrm{D}$ reduction in average $\mathrm{K}$ were observed at 3 months postoperatively and maintained throughout the follow-up period.

UCVA improved by ten lines for both eyes at the week 1 postoperative visit, and the postoperative UCVA was the same as the preoperative BCVA; these results were maintained throughout the follow-up period.

There was a change in the type of astigmatism to withthe-rule one; the steepest keratometry values were at $84^{\circ}$ and $89^{\circ}$ for the right and left eyes, respectively. 
A

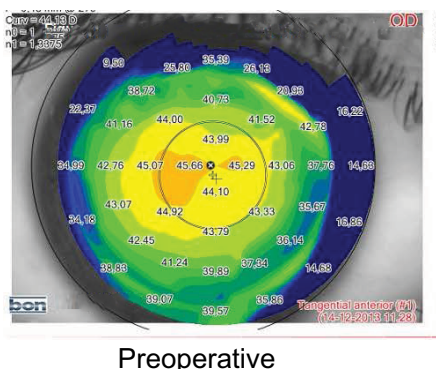

B

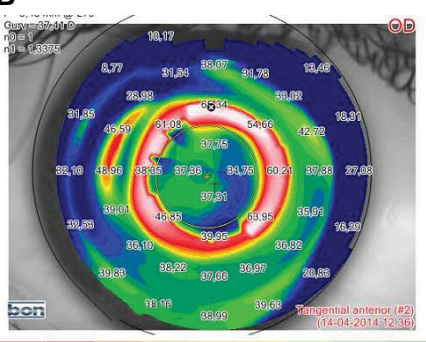

4 months postoperative
C

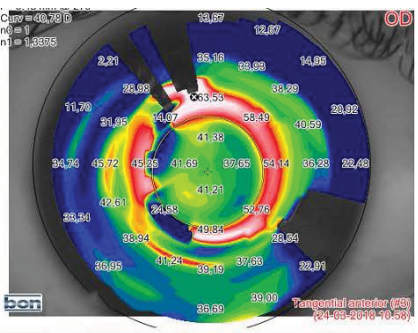

4 years postoperative

Figure I (A) Preoperative and (B and C) postoperative anterior tangential map of the right eye showing the flattening effect of MyoRing.

Regarding the final results at postoperative year 4, UCVA was 0.6 for both eyes, with no further correction; hence, BCVA was 0.6 for both eyes. The final auto-refraction (Topcon KR-800s; Topcon Medical Systems, Oakland, NJ, USA) results were $-1.00 \mathrm{c} \times 172^{\circ}$ and $-1.00 \mathrm{c} \times 180^{\circ}$ for the right and left eyes, respectively.

There were no intraoperative or postoperative complications, and the patient was pleased with the results of his right eye, and furthermore, he insisted on having his other eye treated by the same method 2 weeks later. The only side effect experienced by the patient was night glare, which was transient and treated by using the topical parasympathomimetic drug, pilocarpine hydrochloride (Cooper) $1 \%$ eye drops, prescribed for use twice daily for 3 months only.

\section{Discussion}

The current case report demonstrates the potential benefit of the use of corneal implantable ring for the correction of myopia and astigmatism in a patient who was not eligible for laser kerato refractive treatment, and had a risk of ectasia, and where phakic intraocular lens implantation was impossible as the ACD was $<2.8 \mathrm{~mm}$.

While corneal ring segment was developed for, and has been limited to, patients with mild myopia $(<4.00 \mathrm{D}),{ }^{9,10}$ its results were unpredictable; therefore, it has been replaced by laser kerato refractive procedures. ${ }^{11,12}$

Daxer was the first to describe the use of intracorneal complete ring (MyoRing) for myopia, using a special pocket maker ultrakeratome for five patients; four of them had satisfactory results, and for the remaining one, the ring was removed because of residual myopia. ${ }^{13}$

The results reported in the current case report are comparable with those reported by Daxer for the four successfully treated cases. In the current case, MyoRing implantation resulted in myopic spherical equivalent reduction from -10.00 to $-1.00 \mathrm{D}$ and from -9.75 to $-0.75 \mathrm{D}$ for the right and left eyes, respectively, at week 1 postoperative follow-up, and both eyes achieved a UCVA improvement of ten lines.

According to Barraquer's law, flattening of the central cornea results from the addition of volume in the mid-periphery of the cornea. Figure 1 shows the flattening effect of MyoRing on SIM K1, SIM K2, and average K, along with the change of corneal astigmatism from against-the-rule astigmatism, with the steepest keratometry at $6^{\circ}$, to with-the-rule astigmatism, with the steepest keratometry at $84^{\circ}$.

The current results provide evidence that MyoRing can improve regular astigmatism. This is additional to its known benefit in improving irregular astigmatism, which was reported for the treatment of KC. ${ }^{14-16}$

The reduction in average $\mathrm{K}$ value after MyoRing implantation in the current case was lower than previously reported $\mathrm{KC}$ values, ${ }^{14-16}$ and there was no continuous improvement in visual acuity throughout the follow-up period as reported in KC..$^{14,16}$ This may be explained by the reduced elastic modulus in the cornea with ectasia. ${ }^{17-19}$

The lamellar cut in pocket formation is of no clinical or biomechanical significance, as long as it is generally closed around the entire circumference, except at the $4 \mathrm{~mm}$ opening for the intracorneal ring implantation. This is in contrast with the Lasik flap cut, which involves the entire circumference, except at the hinge; hence, the flap adds nothing to the postoperative corneal biomechanical stability. ${ }^{20,21}$

The advantages of the procedure used in the current case are its safety and reversibility. Hence, rather than removing tissue from the central cornea, tissue was added to the midperiphery. In this way, the corneal biomechanics was strengthened rather than weakened; therefore, from a biomechanical perspective, MyoRing acts as a second limbus within the cornea and divides the force acting on the cornea into two 
areas, where the corneal lamellae are arranged orthogonally toward the peripheral cornea after MyoRing implantation, and assume a circular direction at the corneal limbus. ${ }^{22}$

Estimates of the strengthening effect after MyoRing implantation showed that it is related to the ring diameter, with estimated strengthening equating between 2 and 3 with ring diameters of 6 and $5 \mathrm{~mm}$, respectively. ${ }^{23}$

The procedure described here is easy to perform, reversible, safe, and effective. The results of our patient were stable throughout the entire 4 years of follow-up, with no regression or postoperative complication.

The only unpleasant side effect experienced by the patient was the night vision problem, which was treated by $1 \%$ pilocarpine eye drops prescribed for use twice daily for 3 months; however, the patient subsequently stopped experiencing this glare and was able to drive his car at night without any issues.

\section{Conclusion}

Given the problems with night vision, MyoRing may only be the treatment of choice for a small number of patients for whom PICL implantation is not possible and laser kerato refractive procedures are contraindicated.

\section{Abbreviations}

$\mathrm{ACD}$, anterior chamber depth;

BCVA, best corrected visual acuity;

$\mathrm{D}$, diopter;

$\mathrm{KC}$, keratoconus;

PICL, phakic implantable collamer lens;

UCVA, uncorrected visual acuity

\section{Disclosure}

The author has no financial interest in any material mentioned in the report and reports no conflicts of interest in this work.

\section{References}

1. Spadea L, Cantera E, Cortes M, Conocchia NE, Stewart C WM. Corneal ectasia after myopic laser in situ keratomileusis: a long-term study. Clin Ophthalmol. 2012;6:1801-1813.

2. Alio JL, Soria F, Abbouda A, Pena-Garcia P. Laser in situ keratomileusis for -6.00 to -18.00 diopters of myopia and up to -5.00 diopters of astigmatism:15-years follow-up .J Cataract Refract Surg. 2015;41(1):33-40.
3. Rattan SA. Clinical and refractive outcomes of toric phakic implantable collamer lens implantation for correction of myopic astigmatism. Kufa Medical Journal. 2017;17(1):28-39.

4. Arne JL .Phakic posterior chamber lenses for high myopia: functional and anatomical outcomes. J Cataract Refract Surg. 2000;26(3):369-374.

5. Alfonso JF, Fernandez-Vega L, Lisa C, Fernandez P, Gonzalez Meijome JM, Montes-Mico R. Collagen copolymer toric posterior chamber phakic intraocular lenses for myopic astigmatism, one-year follow up. J Cataract Refract Surg. 2010;36(6):568-576.

6. Sanders DR, Schneider D, Martin R, et al. Toric implantable collamer lens for moderate to high myopic astigmatism Ophthalmology. 2007;114(1):54-61.

7. Guell JL, Rodriguesz-Arenas AF, Gris O, Malecaze F, Velasco F. Phacoemulsification of crystalline lens and implantation of intraocular lens for the correction of moderate and high myopia: 4 years follow up. J Cataract Refract Surg. 2003:29(1):34-8.

8. Fernandez-Vega L, Alfenso JF, Villacamp T. Clear lens extraction for the correction of high myopia. Ophthalmology. 2003;110(12):2349-54.

9. Nose W, Neves RA, Schanzlin DJ, Belfort R. Intrastromal corneal ringone year results of first implants in humans :a preliminary nonfunctional eye study. Refract Corneal Surg. 1993;9(6):452-458.

10. Ruckhofer J, Stoiber J , Twa MD, Grabner G. Correction of astigmatism with short arc-length intra stromal corneal ring segments: preliminary results. Ophthalmol .2003;110(3):516-524.

11. Trokel SL, Srinivasan R, Braren B. Excimer Laser surgery of the cornea. Am J Ophthalmol. 1983;96(6):710-715.

12. Seiler T, Berlin MS, Bende T, Trokel S. Excimer laser keratectomy for correction of astigmatism. Am J Ophthalmol .1988;105(2):117-120.

13. Daxer A .Corneal intrastromal implantation surgery for the treatment of moderate and high myopia. J Cataract Refract Surg. 2008;34(2):194-198.

14. Rattan SA. Simultaneous complete intracorneal ring implantation with intrapocket collagen cross-linking for treatment of keratoconus .The Iraqi Postgraduate Medical Journal. 2015;14(3):355-361.

15. Jabbarvand M, Salamatrad A, Hashemian H, Mazloumi M, Khodaparast M, Aldave A. Continuous intracorneal ring implantation for keratoconus using Femtosecond Laser. J Cataract Refract Surg. 2013;39(7):1081-1087.

16. Daxer A, Mahmoud HM, Venkateswaran RS. Corneal cross-linking and visual rehabilitation in keratoconus in one session without epithelial debridement: a new technique. Cornea. 2010;29(10):1176-1179.

17. Andreassen TT, Simonsen AH, Oxlund H. Biomechanical properties of keratoconus and normal cornea. Exp Eye Res. 1980;31(4):435-441.

18. Nash IS, Greene PR, Foster CS. Comparison of mechanical properties of keratoconus and normal cornea .Exp Eye Res. 1982;35(5):413-424.

19. Edmund C. Corneal elasticity and ocular rigidity in normal and keratoconus eyes. Acta Ophthalmol. 1988;66(2):134-140.

20. Reinstein DZ, Archer TJ, Randleman JB. Mathematical model to compare the relative tensile strength of the cornea after PRK, LASIK, and small incision lenticule extraction. Refract Surg. 2013;29 (7):454-460.

21. Ortiz D, Pinero D, Shabayek MH, Arnalich-Montiel F, Alio JL. Corneal biomechanical properties in normal, post -laser in situ keratomileusis , and keratoconic eyes. J Cataract Refract Surg. 2007;33(8):1371-1375.

22. Aghamohammadzadeh H, Newton RH, Meek KM. X-ray scattering used to map the preferred collagen orientation in the human cornea and limbus. Structure. 2004;12(2):249-256.

23. Daxer A .Biomechanics of the cornea. Int J Keratoconus and Ectatic Corneal Dis. 2014;3(2):57-62.
International Medical Case Reports Journal

\section{Publish your work in this journal}

The International Medical Case Reports Journal is an international, peer-reviewed open-access journal publishing original case reports from all medical specialties. Previously unpublished medical posters are also accepted relating to any area of clinical or preclinical science. Submissions should not normally exceed 2,000 words or

\section{Dovepress}

4 published pages including figures, diagrams and references. The manuscript management system is completely online and includes a very quick and fair peer-review system, which is all easy to use. Visit http://www.dovepress.com/testimonials.php to read real quotes from published authors. 